\title{
DESIGN OF UNMANNED GRENADE TAMER PROTOTYPE WITH WIRELESS CONTROL
}

\author{
Aris Tri lka Rahmadi, Ayip Rivai Prabowo, Ali Mashudi, Luqman Arif \\ Indonesian Naval Technology College, STTAL \\ Bumimoro-Morokrembangan, Surabaya 60187, Indonesia
}

\begin{abstract}
Puslatdiksarmil is a military training and basic education center. To support the trainer in securing the grenade during the grenade throwing exercise, the author made "Design of Prototype Unmanned Grenade Tamer with Wireless Control. This tool is used to assist the trainers in the implementation of handling unexploded grenades, by placing a detonator on the grenade then blasting. In the robot control application is very necessary in everyday life and is very helpful in human activities that are dangerous and difficult to do by humans and therefore we need an application that can control the robot remotely. In this Final Project, a robot has been designed that can be controlled remotely by air or wireless media as an application of a grenade tamer robot. Where the design of this robot will use an integrated robot with an actuator to drive the robot, a camera to monitor the location of objects and its surroundings, and a wireless module that has been connected with the 2.4 Ghz Tranciever so the robot can now be monitored remotely to perform operations.
\end{abstract}

Keywords: Unmanned, Wireless, 2.4Ghz Frequency

\section{INTRODUCTION}

Center for education and military training is tasked with assisting commander command of education and training of the Indonesian national army in coordinating, supervising and controlling schools in the Kodiklatal Puslatdiksarmil. One of the basic military training taught is the practice of throwing grenades, the trainer still uses a human subject to pick up a grenade when it is found edema when it is finished throwing and the results do not explode perfectly (Siswandi, 2015).

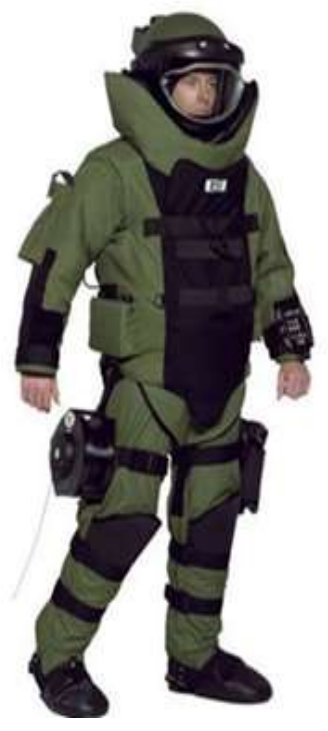

Fig.1 Body Armor
The edema grenade incident was an instructor and guide for Indonesian Navy students, chief sergeant marines Siswandi who had to be willing to lose both hands, even though she was wearing Body Armor in figure 1. or body armor to secure a non-explosive grenade. (Official, 2015)

Based on the background above, the authors plan to make Prototype Unmanned Grenade Tamer with wireless control, Unmanned Grenade Tamer is a tamer grenade robot equipped with arms and gripper, then Unmanned Grenade Tamer is applied to a support tool to assist the instructor in his duty to train students Navy soldiers.

\subsection{Formulation of the problem}

Based on the background, it can be formulated how to design the tool as simple as possible according to the expected functions and specifications, namely:

a. How to design control mechanisms on the arm and Base Tank of the Unmanned Grenade Tamer.

b. Calculates power consumption on the Unmanned Grenade Tamer. 


\subsection{Research purposes}

Based on the formulation of the problem, the writer has a goal in carrying out the design of a remote control control system:

a. Create an overall Unmanned Graned Tamer control design.

b. Selection of the right battery / Accu and according to the Unmanned Graned Tamer.

\section{MATERIALS AND METHODOLOGY}

\subsection{Previous research}

Relevant research or can be called previous research provides an overview of the tools that have been made or only about the analysis of a system that is almost the same. So that in making tools we have a picture and comparison. Relevant research can we take the reference from an international journal or campus journal published. Here the researcher will present a number of previous studies that can be used as references or to be developed. In general to secure unexploded grenades the soldiers or trainers use conventional tools, such as wood or bamboo which are designed to put destructive explosives on the unexploded grenades. After searching for references from various combat units, no specific tool was found to secure the unexploded grenade, so the conventional method was still used. In 2016, D3 Mechanical Engineering Force 9 naval technology high school made a stick manipulator design equipped with a gripper to move and place explosives with certain loads using an electromagnetic system. The tool is the development of existing equipment in the field (Suratno, 2016). Previously at the training location using bamboo and hooks as a tool to place explosives. For tools designed to develop tools before, the operation of the tool must still be manned directly by the operator. With a $3800 \mathrm{~mm}$ stick length, operators still need to be equipped with Body Armor.
Build Design in 2017 prototype control of this robot arm using a $2.4 \mathrm{Ghz}$ wireless interface. From the results of this research is the realization of a prototype model. Robot arms are used as learning media in robotics courses. The control system used is a $2.4 \mathrm{Ghz}$ wireless interface (Agung Gde Ekayana, 2017). While the robot that will be made by the author is in the form of a prototype which can later be applied in the Purboyo Puslatdiksarmil training field, using a 2.4 Ghz frequency via Radio control with remote control up to a maximum of 160 meters without building obstacles.

\subsection{Theoretical basis}

The theoretical foundation that we discussed is our basis in preparing reports, planning and implementing the system plans and tools that we will build.

\subsubsection{Control system}

Collection of several tools used to govern and regulate the state of a system so that it can adjust according to our thinking (Prihatmoko, 2016). There are 2 types of control systems, namely manual control systems and automatic control systems.

a. Manual control system

For human control, it still acts as an operating operator.

b. Automatic control system

Automatic control system is a system still carried out by machines or equipment that work independently according to parameters that have been set by humans and work under human supervision.

In addition to being divided according to the type of control system is divided according to the type of network of the system itself, including open network control systems and closed network systems.

1) Open network control system 
Open network control system is a control system in which the amount of output produced has no influence on its input.

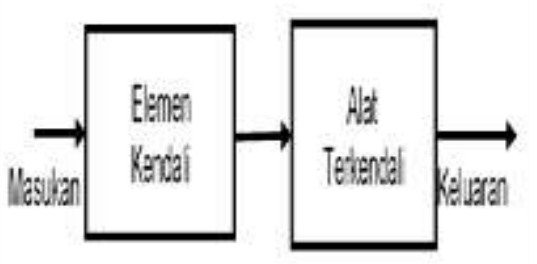

Fig.2 Diagram of an Open Network Control System

(Source: Self-processed Results)

2) Closed network control system

Closed network control system is a controller that has feedback from the outside and is used as a comparison at the input system and serves to minimize the error value.

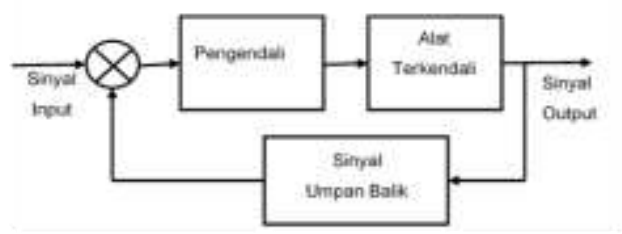

Fig.3 Diagram of a Closed Network Control System

(Source: Self-processed Results)

\subsubsection{Remote Control}

Remote Control is an electronic equipment that is used to operate the device from a long distance. The remote control can also be abbreviated as "remote". The term Remote also often refers to "controller", "donker", "doofer", "zapper" "click-buzz", "box", "flipper", "zippity", "clicker" or "changer". Remote control is generally used to access commands from a distance to electronic devices or other electronic items such as audio and DVD players. These devices are usually for Remote control, are small objects that are held with several buttons to operate various settings menus, such as television channels, volume and track numbers. In devices with controls like this, most are in modern electronics. For the control functions of devices that are controlled while having only a few basic controls that have remote control. Infrared signals and radio signals Mostly used for remote control communicating with their respective devices. As a power supply it still uses a small AAA battery or AA.

The remote control has all the control functions of the device being controlled while the device itself has only a handful of important main controls. Radio frequencies and infrared signals are generally still used as remote controls and communicate with electronic devices. In the modern era remote control is very much needed and remote control devices are becoming the items of great interest in the sale of electronic goods today.

Universal Remote is a remote control that can be programmed and used for all types of equipment that have infrared sensor facilities and can be used for general everyday electronic goods such as household appliances. Many electronic devices use a universal remote, this controller still uses codes for operating with electronic devices. In 1898 Nikola Tesla's Patent number 613,809 developed its own earliest remote control using radio waves. In 1898, a radio boat that could be controlled via remote control was exhibited to the world, during the electricity exhibition in Madison Square Garden. Tesla mentioned his boat "teleautomaton".

In 1903, Leonardo Torres Quevedo at the Paris Academy of Science presented a Telekino, and an experimental demonstration was made. In the United States, France, Britain and Spain. Robot The Telekino robot that can be controlled by electromagnetic waves At the same time he obtained a patent. With the Telekino, the principles of modern wireless remote-control operation were laid down by Torres-Quevedo and as a pioneer in the field of remote control. In 1906, in front of the king and a large community of people who saw, Torres had successfully exhibited the findings at the port of Bilbao, controlling the boat from the 
seashore, and subsequently it would be tried to apply in Telekino for torpedoes and projectiles, due to lack of project funds forced to stop.

The first remote control aircraft model in 1932, the technology used to remotely work intensively, during the Second World War, the German missile Wasserfall was one of the results. In the late 1930s, at that time several remote control radio manufacturers were offered for some of the more sophisticated and modern models. The battery that can be operated via a frequency radio transmitter is the Philco Control (1939), and made it the first time that a wireless remote control for electronic devices. This remote control is the result of technological developments made by humans with the aim of developing innovative, fast and practical results. Some supporters of remote control include

a. Wave. Waves are a symptom of propagation from a vibration, the wave is divided into 2 based on the intermediary.

\section{1) Mechanical Waves}

Waves which if in the sequence of propagation still require intermediaries should not occur so-called mechanical waves.

\section{2) Electromagnetic Waves} Electromagnetic waves are waves which in the sequence of propagation do not require intermediates, meaning that even though there are no intermediaries these waves can still propagate.

b. Frequency. During one second the vibration is a frequency, known as the Herzt unit $(\mathrm{HZ})$. In the current era the frequency is very closely related to the discussion relating to sound or with the medium of communication. In physics frequency is divided into 2 types, namely Radio frequency and Sound Frequency.

\section{1) Radio Frequency}

Radio Frequency is a frequency that refers to electromagnetic spectra obtained by alternating current input to an antenna. Radio Frequency is commonly known as AM radio frequency and FM radio frequency.

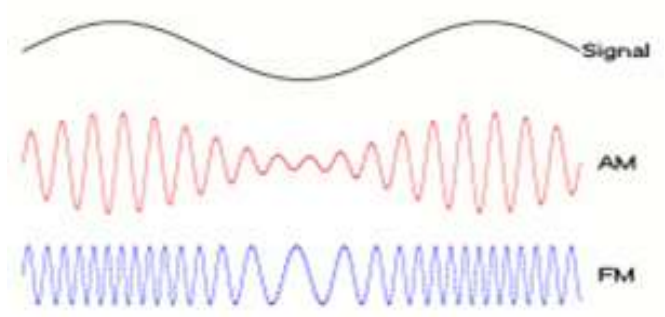

Fig.4 Differences in FM and AM frequencies (Source: http://ngs-electrical.blogspot.com)

\section{2) Audio Frequency}

Audio Frequency can be called Sound Frequency, the frequency of vibrations that can be heard by humans. These waves are divided into 3 types, including infrasound frequencies (0 to $20 \mathrm{~Hz}$ vibrations), Audible Frequencies (20 to $20,000 \mathrm{~Hz}$ vibrations) and ultrasonic frequencies (vibrations above $20,000 \mathrm{~Hz}$ ).

c. Modulation. Modulation is the process by which two wave signals are combined, usually a high frequency signal with a low frequency signal. Two types of Modulation namely, Digital Modulation and Analog Modulation.

\section{1) Analog Modulation}

Called data signals can also be in the form of continuous waves or waves that are continuously continuous is analog modulation. Analog modulation is divided into three, among others, Frequency Modulation (FM), Amplitude modulation (AM), and Phase Modulation (PM).

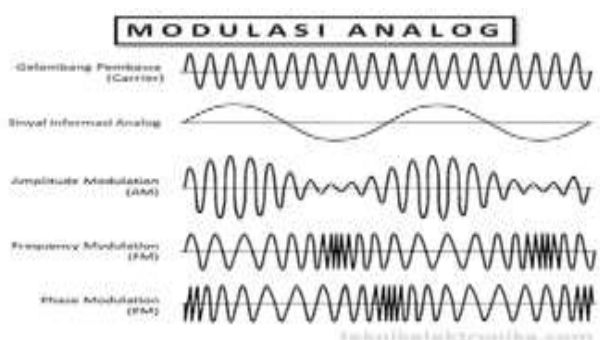

Fig.5 Analog Modulation (Source: https://teknikelektronika.com) 
Digital modulation is a signal in the form of pulses and has two states: 0 (On) and 1 (Off), the advantage of digital modulation is that the information process is fast, easy to accurate.

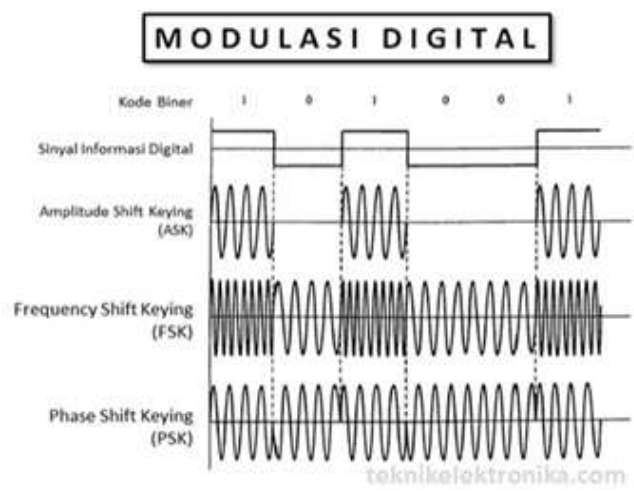

Fig.6 Digital Modulation

(Source: https://teknikelektronika.com)

\subsubsection{Radio Communication Transceiver}

Radio transmitters are at the same time useful doble for radio receivers that are used as communication purposes also called Radio communication transceivers. Which consists of a transmitter and receiver parts which are arranged in an integrated manner. At the beginning of the latest generation, the transmitter system and the receiver and receiver parts are arranged in a separate way that is a separate part and can work alone. For now, the two parts are integrated, functioned in turn. Vibration generator oscillator is found on a simple transmitter (Transmitter).

a. Transmitter (Remote Control)

Wireles communication that functions to send data to other places in the form of radio waves is part of the system also called the Transmitter. The principle and function of the work of the transmitter is that there is an induction of a magnetic field from a potential source then causes current and induces a connected circuit.

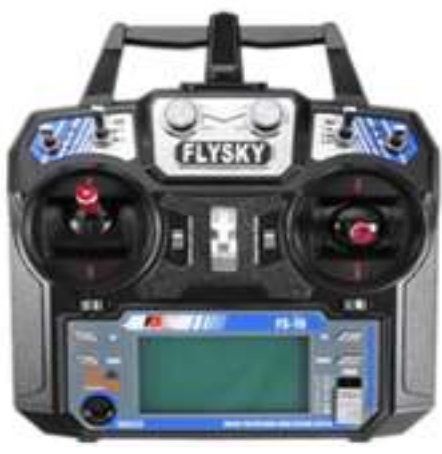

Fig.7 Flysky i6 Transmitter Module (Source: https://id.aliexpress.com)

\section{b. Receiver}

The signal receiver from the signal given from the transmitter (remote) can then be controlled according to our wishes without wires also called receivers.

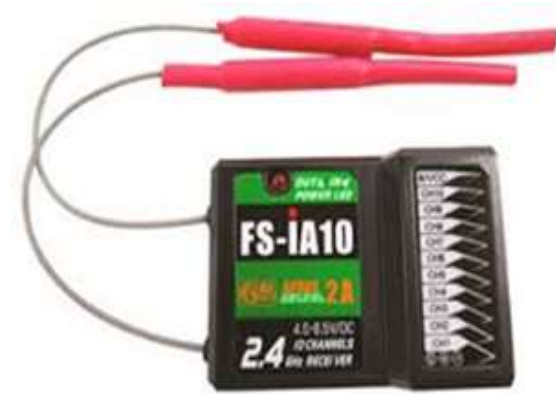

Fig.8 Flysky Receiver Module 16 (Source: https://images.app.goo.gl/)

\subsubsection{Electric current}

Electric current is the ratio of the input voltage to the resistance of the electrical circuit. Electric current is formed by the flow of electric charges flowing in a certain medium, the distribution of electric current is divided into 2 parts: Direct electric current (Direct Curent) and alternating electric current (Alternathing Current). The unit of electric current is Ampere. Likewise, with voltage, voltage is the product of current and electrical resistance. Electric voltage is formed by the flow of electric current with electrical resistance. Electrical voltage is divided into 2 parts: direct voltage (Direct Voltage) and alternating current voltage. The unit of voltage is Voltage (Panjaitan, 2018). Electric Current is a Comparison of input voltage with Electrical Resistance, can be formulated by: 
The formula of electrical power in the study of electronics:

$$
P=V x I
$$

Where:

$$
\begin{aligned}
& \mathrm{P}=\text { Electric Power }(\mathrm{W}) \\
& \mathrm{V}=\text { Electric Current Voltage }(\mathrm{V}) \\
& \mathrm{I}=\text { Electric Current Strength }(\mathrm{A})
\end{aligned}
$$

The greater voltage or amperage voltage causes a large amount of power.

The application of the formula in a triangle known as the Law Triangle is as follows:

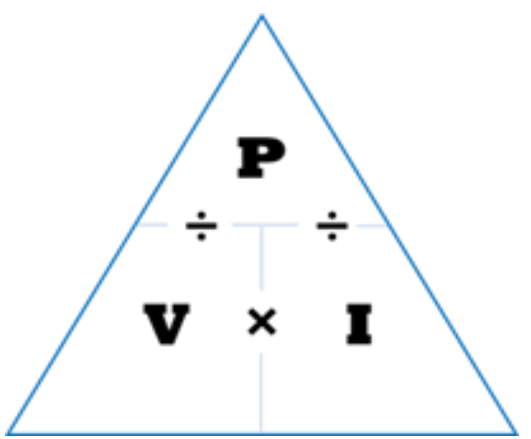

If you want to find a voltage, you can place your finger on all of the ' $V$ ' spaces. So it will be seen:

$$
\mathrm{V}=\mathrm{P} / \mathrm{I}
$$

Where:

$\mathrm{P}=$ Electric Power $(\mathrm{W})$

$\mathrm{V}=$ Electric Voltage $/$ Potential Difference $(\mathrm{V})$

$\mathrm{I}=$ Electric Current Strength $(\mathrm{A})$

Likewise, if we want to find Flow, we can place our finger on all of the space I 'spaces. So it will be seen

$$
\mathrm{I}=\mathrm{P} / \mathrm{V}
$$

Where:

$$
\begin{aligned}
& P=\text { Electric Power }(W) \\
& V=\text { Electric Voltage }(V) \\
& I=\text { Electric Current Strength }(A)
\end{aligned}
$$

\subsubsection{Electrical power}

Electric Power and the Formula in the study of electronics there are some material about electrical power. Electricity is also explained in terms of the electricity class that is also familiar. During this time we also often hear and encounter this term. Electric power is the amount of energy that can be absorbed by an electrical circuit. In calculating the amount of electric power can also use Ohm's legal formula and the general electric power formula to make it easier. This is because the amount of electrical power is related to energy and time of occurrence. But that's not all, electrical power can be related to the potential difference and the strong electric current.

For the understanding of electric power can also be seen that based on the concept of business is a useful effort and each time can move the charge with the amount of energy. Based on her explanation above, the electric power formula was obtained:

$$
P=E / T
$$

Where:

$$
\begin{aligned}
& P=\text { Electricity (Watts) } \\
& E=\text { Electrical Energy (Joules) } \\
& t=\text { Time (seconds) }
\end{aligned}
$$

Based on the formula that was written above, it can be seen that electrical power has the symbol $\mathrm{P}$, which means Power. Electric power has a SI unit is Watt. Watt also has the same meaning, Joule. The following are Watt units that can be used for example:

1 milli Watt $=0.001$ Watt

1 kilo Watt $=1,000$ Watt

1 Mega Watt $=1,000,000$ Watt

Apart from the electric power formula that has been written above, there is also a general formula for calculating the amount of power in a circuit. Below this is the general formula for electric power in an electric circuit.

$$
\begin{aligned}
& P=V x \mid \ldots \ldots . \\
& P=I^{\wedge} 2 x R \\
& P=V^{\wedge} 2 / R
\end{aligned}
$$

Where:

$$
\mathrm{P}=\text { Electric Power }(\mathrm{W})
$$


$\mathrm{V}=$ Electric Voltage $(\mathrm{V})$

I = Electric Current Strength $(\mathrm{A})$

$\mathrm{R}=$ Electrical Resistance $(\Omega)$

The calculation of electric power is not only known variable that is already known. But there are also problems where variables must exist first. The basic formula in calculating electric power is $\mathrm{P}=\mathrm{Vx}$ I, but can calculate electric power using Ohm's law equation. In Ohm's law equation has the formula $V$ $=I \times R$. So if in the matter of calculating the amount of electric power known only electrical resistance and strong electric current then can use the equation formula below:

$$
\begin{aligned}
& P=V x \mid \ldots \ldots . . \\
& P=(\mid x R) x \mid \ldots \\
& P=I^{\wedge}(2) . R
\end{aligned}
$$

The formula that has been explained can be used to find the amount of electrical power, but if it is known that only electrical resistance and voltage, then you can use the formula below:

$$
\begin{aligned}
& P=V x I \ldots \ldots . . \\
& P=V x V / R . \\
& P=V^{\wedge} 2 / R
\end{aligned}
$$

Existing formulas can be used to find the amount of electric power. Electricity is divided into two parts according to the current, DC Current (Direct Current) and AC Current (Alternating Current).

\section{a. AC Current (Alternating Current).}

AC current (Alternating Current), which is the amount of electric current and the direction of the current is changing or alternating back and forth periodically. The source of electric power is generated from electricity generators and is usually used for industrial and home appliance storage (accumulator)

A secondary element or cell that is the source of direct current that can convert chemical energy into electrical energy is called a battery or Storage Battery. The battery is an electrochemical element that can have an effect on the reaction substance, so it can also be called a secondary element. The positive pole for the battery uses the oxide plate while the negative pole uses the lead plate while the electrolyte solution is sulfuric acid solution. If the battery is used, chemical reactions occur that can cause sedimentation in the anode (reduction) and cathode (oxidation). Cause, in a certain time between the anode and the cathode there will be no potential difference, the conclusion is the empty battery.

So that the battery can be used again, it must be filled by flowing through the electric current in the opposite direction from the electric current issued by the battery itself. If the battery is filled then an electric charge accumulates. Battery power or called ampere hour occurs because of the collection of the amount of electric charge. Actually, the use of batteries can not remove all the energy stored by the battery itself. Therefore, the battery has a yield or efficiency.

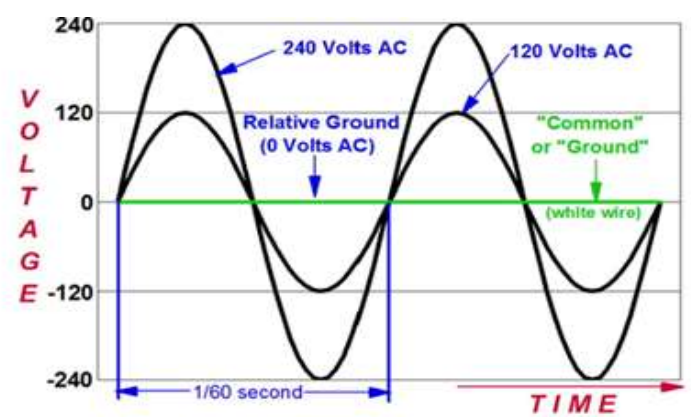

Fig.9 AC Current Signal (Source: http://www.masputz.com)

b. DC Current (Direct Current)

DC current (Direct Current) is the electric current where the direction of the current is direct, the flow of energy from high potential to lower potential. The source of electricity is produced from several sources, including batteries, batteries, etc. 

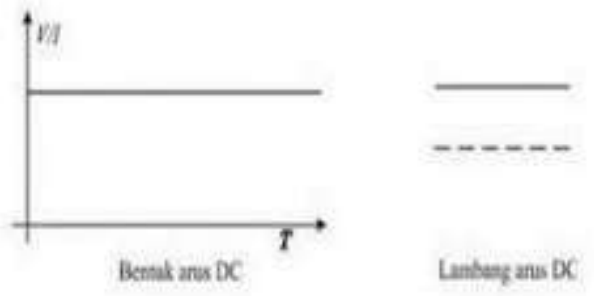

Fig.10 DC Current Signal

(Source: http://www.masputz.com)

\subsubsection{Battery}

A device that can convert the stored chemical energy to electrical energy that can be used by an electronic device called a battery. Some portable electronic devices such as flashlights, laptops, cellphones, or remote controls that are used are batteries for their electrical power sources. With batteries, a person does not need a power cord connection in order to turn on an electronic device so that it can be easily carried anywhere (Nur Shabrina, 2014)

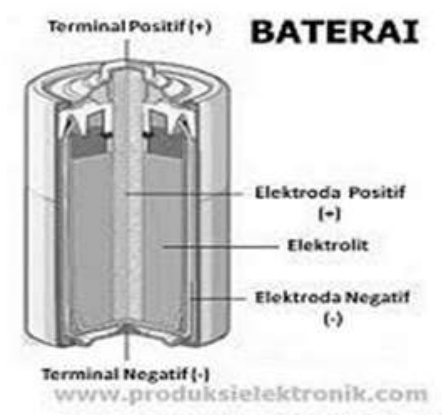

Fig.11 Batteries

(Source: www.Productionelektron.com)

Accumulator (accumulator) A secondary element or cell which is the source of direct current that can convert chemical energy into electrical energy called a battery or Storage Battery. The battery is an electrochemical element that can have an effect on the reaction substance, so it can also be called a secondary element. The positive pole for the battery uses the oxide plate while the negative pole uses the lead plate while the electrolyte solution is sulfuric acid solution. If the battery is used, chemical reactions occur that can cause sedimentation in the anode (reduction) and cathode (oxidation). Cause, in a certain time between the anode and the cathode there will be no potential difference, the conclusion is the empty battery. So that the battery can be used again, it must be filled by flowing through the electric current in the opposite direction from the electric current issued by the battery itself. If the battery is filled then an electric charge accumulates. Battery power or called ampere hour occurs because of the collection of the amount of electric charge. Actually, the use of batteries can not remove all the energy stored by the battery itself. Therefore, the battery has a yield or efficiency.

\subsection{METHODS}

\subsubsection{Research design}

This is a research in which this research was carried out by carrying out development aimed at minimizing the occurrence of accident victims of personnel when retrieving / securing edema grenades in the field of training for military basic education centers. However, this also includes engineering research that applies knowledge and knowledge to become a design that subsequently obtains performance in accordance with established requirements. The design is a design that is combined with scientific methods to become a system that meets certain specifications.

In this research, a control system design on Unmanned Grenade Tamer will be carried out. Control is done by using the remote control that is controlled by the operator. In the design of the Unmanned Grenade Tamer control system, a control control mechanism will be made using a servo motor for arm drive and a DC motor for Base Tank drive that is controlled by the operator using a remote. The excess plan of the design of this tool is that it can be controlled remotely without obstructing the building with a maximum distance of 160 meters and is equipped with an object detection camera. While the shortcomings in this 
design are not equipped with GPS object markers and the power supply of this tool depends on the DC source.

\subsubsection{Research procedure}

In this research procedure will be explained for the time and place of research, tools and materials that will be used in the manufacture of these tools, then the design of the study, collecting data and processing data.

\subsubsection{Time and Place of Research}

The research will be carried out after the completion of the proposal seminar in July 2019, while the place of manufacture and design of the tool will be carried out at the STTAL Integrated Laboratory of Dana Island.

\subsubsection{Research Tools and Materials}

In the research and design process, equipment and materials are needed as follows:

Table 1 Tools and material

\begin{tabular}{|c|c|c|}
\hline NO & $\begin{array}{l}\text { TOOLS AND } \\
\text { MATERIALS }\end{array}$ & MARK \\
\hline 1 & Tang Ampere & Nankai \\
\hline 2 & $\begin{array}{ll}\text { Elektrik Speed } \\
\text { Control }\end{array}$ & $360 \mathrm{~A}$ \\
\hline 3 & Motor DC 2 pcs & $\begin{array}{l}\text { EPS } 12 \text { Volt } 104 \\
\text { watt }\end{array}$ \\
\hline 4 & $\begin{array}{l}\text { Motor Servo savox } \\
6 \text { pcs }\end{array}$ & $20 \mathrm{~kg}-40 \mathrm{~kg}$ \\
\hline 5 & Buck Converter & 15 Ampere \\
\hline 6 & Pcb & $12 \mathrm{~cm} \times 25 \mathrm{~cm}$ \\
\hline 7 & Transmitter & $\begin{array}{l}\text { Flysky is i6 } \\
2.4 \mathrm{Ghz}\end{array}$ \\
\hline 8 & Receiver & $\begin{array}{l}\text { Flysky iA } 10 \mathrm{~B} \\
2.4 \mathrm{Ghz}\end{array}$ \\
\hline 9 & Aсcu & 12 Volt \\
\hline 10 & Solder & $\begin{array}{l}\text { Opticcom } \\
\text { watt }\end{array}$ \\
\hline 11 & Avo meter & Sanwa \\
\hline 12 & Tool set & Tekiro \\
\hline 13 & Obeng (set) & Tekiro \\
\hline 14 & Tang kombinasi & Tekiro \\
\hline 15 & Cutter & Kenko \\
\hline
\end{tabular}

The usefulness of the tools used in 15 tools and research materials are as follows: a. Pliers Amperes is useful for measuring electrical current in a conductor cable through which an electric current is passed.

b. Electronic Speed Control is used to regulate the speed of a DC motor.

c. 2 pcs DC motors are used to drive the Base Tank main chain wheels.

d. Servo motors are used to move electronic devices into a mechanical movement to the desired position.

e. Step Down is used to reduce DC current or mains voltage.

f. PCBs are used to assemble the needs of different types of electronic components so that later they do not use cables from one another.

g. Transmitter or Remote Control is used to control a device by sending a signal to the receiver, the receiver.

h. The receiver is used as a signal catcher from the remote so that it can be controlled according to our wishes without wires. Receivers in toy airplane or car models function to receive control signals.

i. Accu is used to provide electrical power to electrical and other electrical systems.

j. Solder is useful for assembling or connecting one electronic circuit to another on a PCB.

k. Avo meter is useful as a tool to measure current (ampere), resistance (Ohm) and voltage (Volts) in the tool.

I. Tool set is used to open and tighten bolts or nuts with precision.

m. Screwdriver set of tools used to loosen or tighten bolts.

\subsubsection{Research design}

This research is a process that will be carried out in stages, namely a design and planning, in order to be able to focus on research, research time, data collection, analysis and presenting research results. Regarding the writing of the results of this study was done descriptively or through descriptions that describe and explain the 
work of the system. This planning and design is illustrated through a flowchart. Here is a flowchart can be seen in figure 12

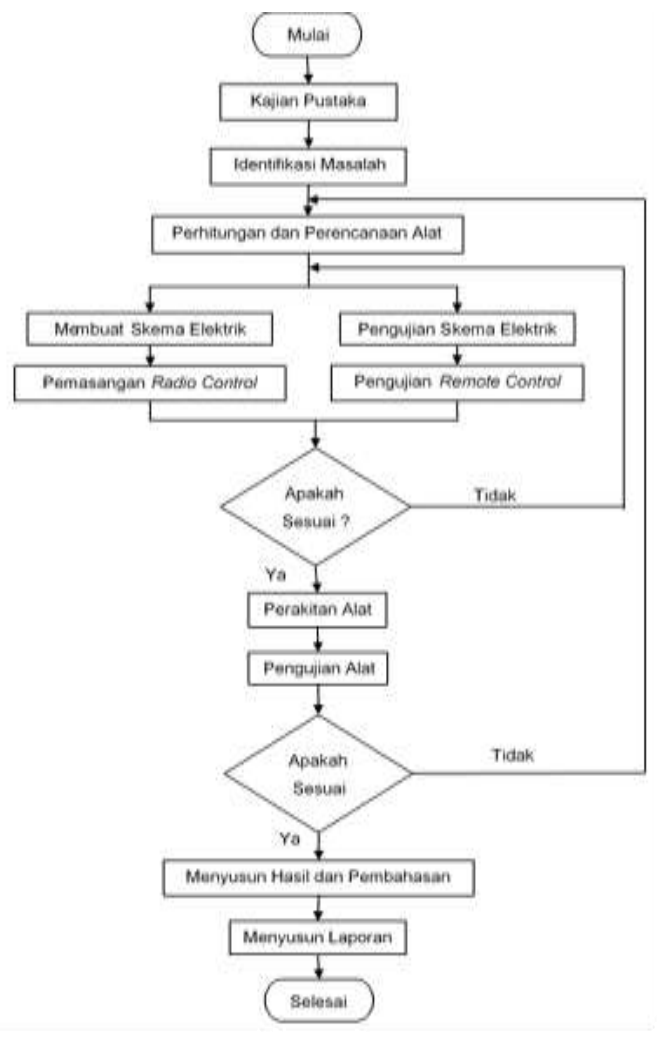

Fig.12 Flowchart of Research Design (Source: Self-processed Results)

In July 2019 the writer began to carry out the design research process. Beginning the author conducted a survey of data collection and observation until the data that the author thinks is sufficient. With some data obtained by the author begins to identify problems that exist in the field in accordance with the current situation. After that the authors carry out a literature review by conducting assistance with the supervisor in the hope of following the next step instructions regarding the calculation and planning of the tool.

After doing assistance the mechanical group does the calculation up to the hardware design and does the following test the control group performs the system design up to the test, for both the mechanical and control tests do the planning until the test is done together, if it is not in accordance with the planning, the process is repeated again, if the results will be as expected, the writer starts with the tool assembly stage, then tests are held again. If the testing phase is stated as expected, the next step is to compile the results of the design and discussion of constraints, then the final project report is prepared and the design planning stage is declared complete.

The Diagram Block Design of Prototype Unmanned Grenade Tamer with Wireless Control can be seen in the Diagram Block of the Prototype of the robot arm in Figure 13

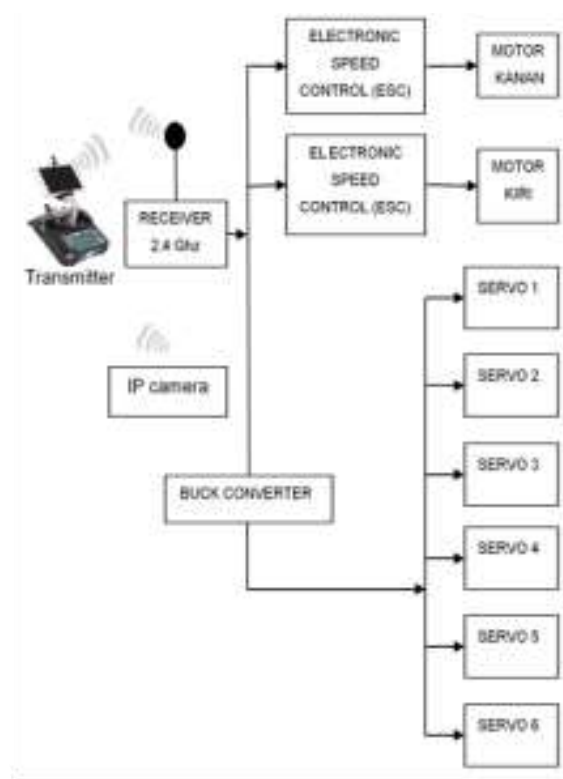

Fig.13 Block Prototype diagram of a robot arm (Source: Self-processed Results)

In the block diagram above, it can be explained that the input from the robot uses the Flysky i6 wireless joystick remote with a frequency of $2.4 \mathrm{Ghz}$. The signal receiver used is the Flysky 10 $\mathrm{CH}$ i6 Receiver with output in the form of a DC motor for wheel drive and servo motor for moving robotic arms.

The DC power consumption needed to operate the robot arm is 6.5 Volts using the 12 VDC Accu which has been reduced by using Buck Converter. The remote control fully functions as input to the Base Tank and robot arm, each robot's movement will be adjusted according to the circumstances or testing. 


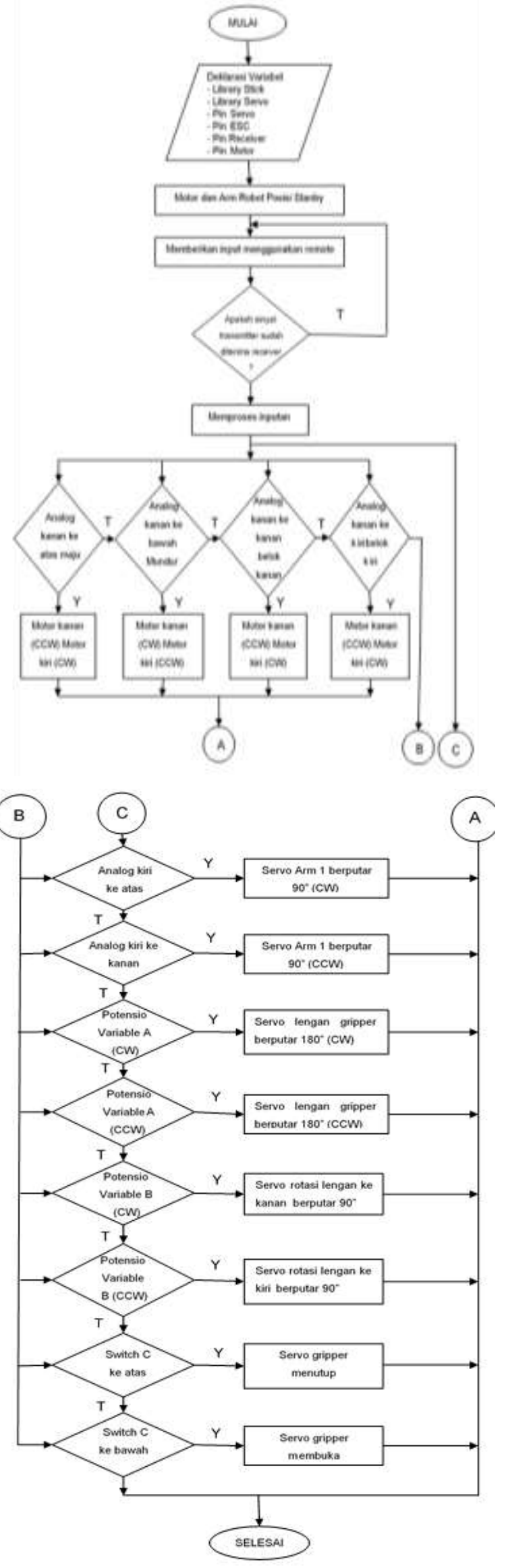

Fig.14 Flowchart Prototype Base and Robot Arm (Source: Self-processed Results)
Figure 14 is an explanation of the flowchart flow for the prototype Base and robot arm. It is explained in the picture above, the order in which the prototype of the robot arm starts to be ignited until it is moved.

\subsubsection{Data collection}

The method used to collect data and information and research on Prototype Unmanned Grenade Tamer Design with Wireless Control is:

a. Data collection by conducting library research that is looking for books or information related to this tool.

b. Conducting consultation and direction / guidance from the guiding lecturer and other sources that can be used as a comparison in designing this tool

c. Looking for reference data that is used in making Prototype Unmanned Grenade Tamer Design with Wireless Control using internet media.

\subsubsection{Data processing}

Furthermore, the data collected by the writer do the data processing, the data processing is by means of the writer series and tests, from the results of the data that the authors have collected then do mathematical calculations on the basis of theoretical science.

\section{RESULT AND DISCUSSION.}

Operational Definition is the determination of various definitions that will be used by the author in research. Definitions of concepts that are still abstract become operational which then facilitate the measurement of these variables. An operational definition can also be used as a definition limit that is used as a guideline for conducting an activity or research work.

\subsection{System planning}

The system design that the author discusses in this chapter is about the design of electronic systems from an integrated mechanical system as a control 
control system. In designing this hardware, the authors designed electronic equipment that supports the work of the Unmanned Grenade Tamer using radio control so that it can be controlled remotely without wires. The hardware design includes the design of the transmitter, receiver and electrical parts for the movement of the Base Tank and the robot arm. The transmitter includes the flysky i6 AFHDS 2A remote with $2.4 \mathrm{Ghz}$ radio frequencies and the receiver uses the 10 Chanel FS iA10B AFHDS flysky receiver. While the movement of the Base Tank chain wheels uses 2 electronic speed controls as speed regulators that are connected to each of the 104 Volt 104 Watt DC motors. In the movement of the robot arm using 6 servo motors. All electrical power needed on this tool is supplied using 12-volt Accu and DC to DC Buck Converters as voltage drops from 12 volts to 6.5 volts to be forwarded to the robot arm servo motor. The system design is carried out both on the remote control and the existing control on the robot.

a. Hardware Design

The design of this tool is a very important part in making tools that will be designed in this thesis. This design is designed with planning based on theory and references which will later relate to tools designed to facilitate the work and analysis of tools. In this chapter, the system design of hardware will be explained. For this hardware design, the authors designed electronic equipment that supports the work of the Unmanned Grenade Tamer. The design of this hardware in the transmitter, receiver, buck converter, servo motor and DC motor. In Figure 4.1, the tool scheme, showing the parts of the electrical system design and control system control of the equipment made, from each part the arrangement of laying positions is explained in order to facilitate workmanship and checking in case of troubleshoot.

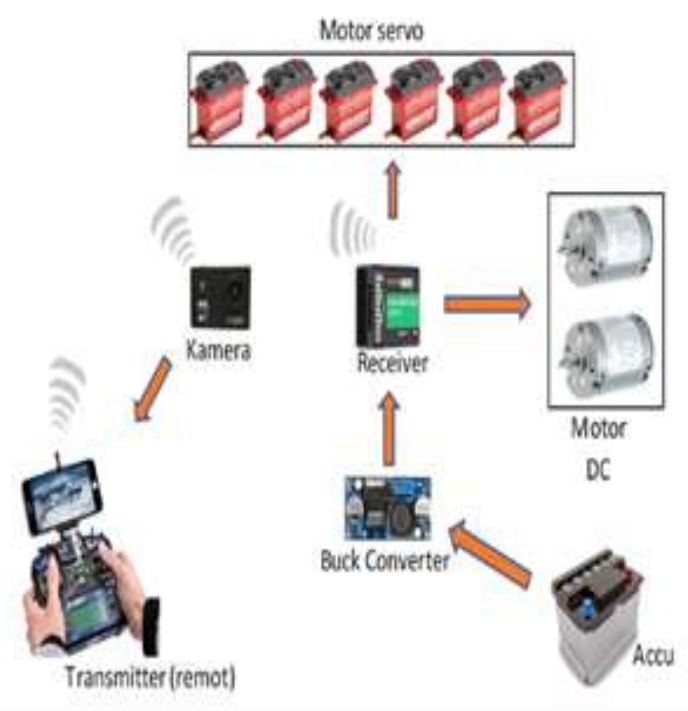

Fig.15 Toolkit Schema

(Source: Self-processed Results)

b. Electrical System Schematic Tool

The electricity scheme that is used using Direct Current (DC) current with 12 Volt power and Buck converter is used to reduce the voltage from DC to DC current then it will be forwarded to the receiver as the receiver signal from the transmitter. Electronic Speed Control as a regulator of the speed of a DC motor, while the servo motor will function as a robotic arm drive. The research system for cable placement and structuring uses a PCB board.

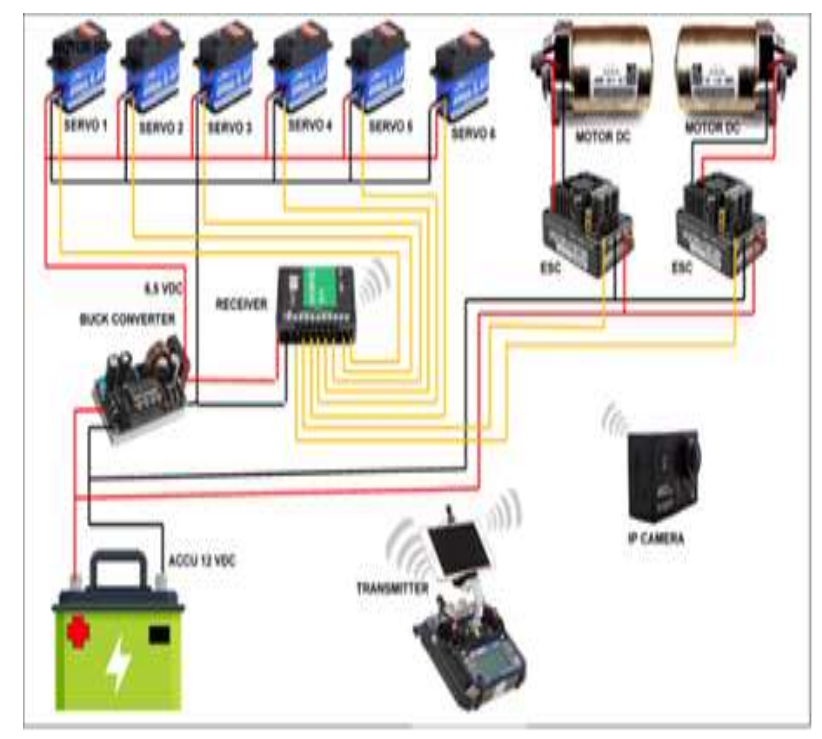

Fig.16 Electrical System Schematic Tool (Source: Processed Sendriri Results) 
c. Design of an Electric Transmitter (Remote Control) System

In this electric transmitter system, the researchers used a series of 2.4Ghz Flysky-i6 $\mathrm{CH}$ Transmitterr sold by the manufacturer. The specifications in this radio control still use 6 channels so a firmware update is needed to meet the needs of using the existing channels on the research tool as many as 8 channels. For the flysky i6 transmitter, it uses a wireless network through the air for the connecting channel that uses a 2.4 $\mathrm{GHz}$ frequency. Work orders are received and then modulated by the transmitter, after the modulation the signal will be sent through the antenna in the form of a radio signal.

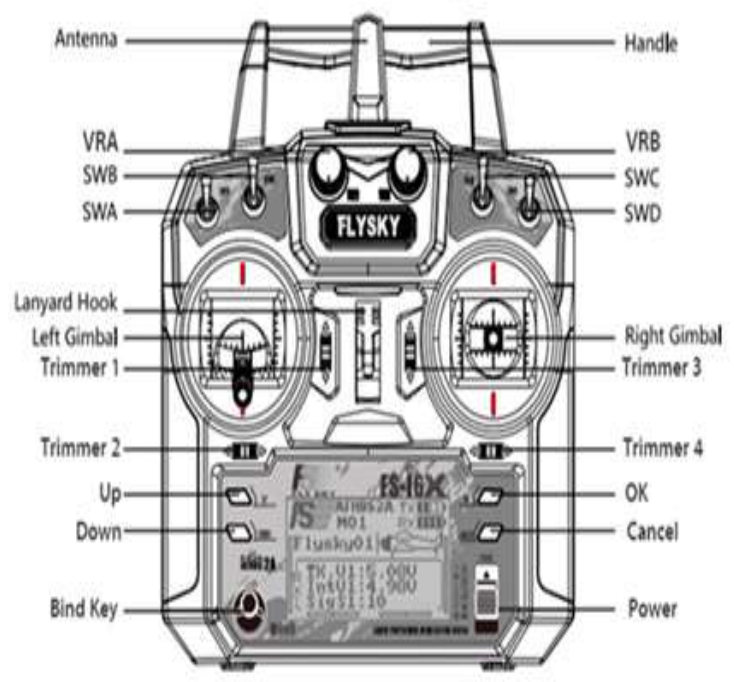

Fig.17 Flysky i6 Transmitter Schema (Source: https://robu.in/product/flysky)

\section{d. Design of the Receiver Electric}

System $2.4 \mathrm{GHz}$ radio signal waves that are emitted are received by the antenna, then modulated by the receiver, the received signal will carry out commands to the DC motor and the servo motor further, the picture can be seen in Figure 18.

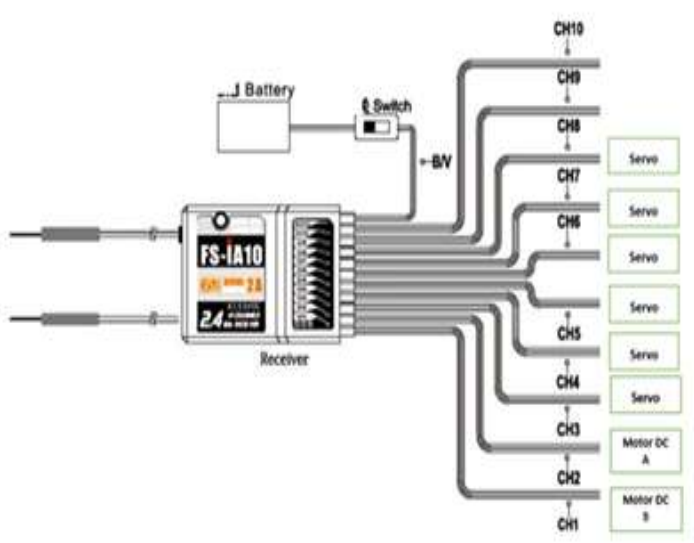

Fig.18 Schematic 2.4Ghz 10CH Flysky Receiver Circuit

(Source: https://picclick.com)

\section{e. Operating Control Design}

The controller control scheme is made to facilitate the preparation, operation and operation of the controller. The remote control controller also consists of an electric speed control circuit and an integrated transceiver. This remote uses a transmitter microcontroller that is connected to the Receiver as a control that works at a voltage of 6 volts, where the power source is obtained from $A A$ AA 1.5 Volt alkaline batteries as many as 4 mounted on the inside of the remote, and the addition of an antenna used as a transmitter and receiver signal from and to remote.

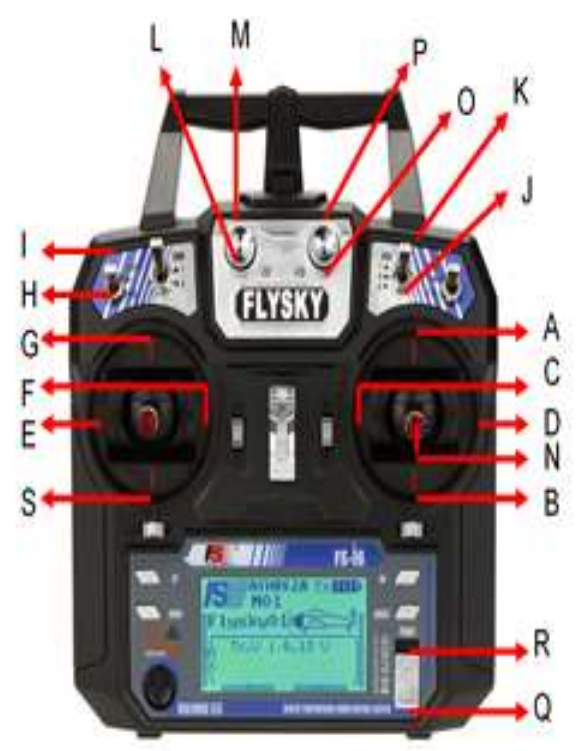

Fig.19 Remote Control Design (Source: Self-processed Results) 
Table 2. Description of the Flysky Joystick Remote Button

\begin{tabular}{|c|c|c|}
\hline COMMAND & BUTTON & INFORMATION \\
\hline $\begin{array}{l}\text { Right and left } \\
\text { wheel control }\end{array}$ & A & Up \\
\hline $\begin{array}{l}\text { Right and left } \\
\text { wheel control }\end{array}$ & B & Reverse \\
\hline $\begin{array}{l}\text { Right and left } \\
\text { wheel control }\end{array}$ & C & $\begin{array}{l}\text { Right forward left } \\
\text { reverse }\end{array}$ \\
\hline $\begin{array}{l}\text { Right and left } \\
\text { wheel control }\end{array}$ & $\mathrm{D}$ & $\begin{array}{l}\text { Left forward right } \\
\text { reverse }\end{array}$ \\
\hline $\begin{array}{l}\text { Servo control arm } \\
2\end{array}$ & $\mathrm{E}$ & Moving up \\
\hline $\begin{array}{l}\text { Servo control arm } \\
2\end{array}$ & $\mathrm{~F}$ & Moving down \\
\hline $\begin{array}{l}\text { Servo control arm } \\
1\end{array}$ & G & Moving up \\
\hline $\begin{array}{l}\text { Servo control of } \\
\text { arm } 4 \text { gripper }\end{array}$ & $\mathrm{H}$ & $\begin{array}{l}\text { Gripper spin } 90 \\
\text { 'cw }\end{array}$ \\
\hline $\begin{array}{l}\text { Servo control of } \\
\text { arm } 4 \text { gripper }\end{array}$ & 1 & $\begin{array}{l}\text { Gripper spin } 90 \\
\text { 'ccw }\end{array}$ \\
\hline $\begin{array}{ll}\text { Servo control } 5 \\
\text { gripper }\end{array}$ & $J$ & Gripper opens \\
\hline $\begin{array}{l}\text { Servo control } 5 \\
\text { gripper }\end{array}$ & $\mathrm{K}$ & Gripper closes \\
\hline $\begin{array}{l}\text { Servo control arm } \\
3\end{array}$ & $\mathrm{~L}$ & Moving down \\
\hline $\begin{array}{l}\text { Servo control arm } \\
3\end{array}$ & M & Moving up \\
\hline $\begin{array}{l}\text { Right and left } \\
\text { wheel control }\end{array}$ & $\mathrm{N}$ & Netral \\
\hline $\begin{array}{ll}\text { Servo control } & 6 \\
\text { rotation } & \\
\text { foundation } & \\
\end{array}$ & $\mathrm{O}$ & $\begin{array}{l}\text { Arm foundation } \\
\text { moves into right }\end{array}$ \\
\hline $\begin{array}{ll}\text { Servo control } & 6 \\
\text { rotation } & \\
\text { foundation } & \\
\end{array}$ & $P$ & $\begin{array}{l}\text { The foundation of } \\
\text { the arm moves } \\
\text { left }\end{array}$ \\
\hline Remote switch & Q & On \\
\hline Remote switch & $\mathrm{R}$ & Off \\
\hline $\begin{array}{l}\text { Servo control arm } \\
1\end{array}$ & S & Moving down \\
\hline
\end{tabular}

\section{f. Electric Power Source Design}

In designing the author's wife using a DC power source, which is the power source that is on the remote remote control and on the Unmanned Grenade Tamer. The author will calculate the consumption of electrical power and power sources on the device designed.

1) Calculate the capacity and Power Consumption in Remote. Based on the specifications listed on the Remote Name Plate,Note: 6 VDC mains voltage transmitter and 1 Ampere electric current. If using the formula (2.5)

$\mathrm{P}=\mathrm{V}$. I

$P=6$ V. $1 \mathrm{~A}$

$P=6$ WS

So every second the control requires $6 \mathrm{Ws}$ of power.

As per the manufacturer's specifications, the power source on the remote control is to use $4 \mathrm{AA}$ batteries with an output power of 6 VDC and the capacity indicated on the storage battery is $1100 \mathrm{mAh}$ (Miliamphere Hour) or equivalent to $1.1 \mathrm{Ah}$, so the total amperage of 4 batteries installed in series are $4.4 \mathrm{Ah}$. Then it can be calculated:

Is known:

Remote power $6 \mathrm{~W}$

Voltage 6V

\subsection{Ah Battery}

If using the formula (2.3)

$\mathrm{I}=\frac{P}{V}$

$\mathrm{P}=$ Electric power in watts $(\mathrm{W})$

$\mathrm{V}=$ Electric voltage in Volt $(\mathrm{V})$

$\mathrm{I}=$ Electric current with units of Amphere (A) $\mathrm{I}=\frac{6 \mathrm{w}}{6 \mathrm{v}}=1 \mathrm{~A}$

Usage time $=\frac{4,4 \mathrm{Ah}}{1 \mathrm{~A}}=4.4$ Hours

Then the remote can standby 4.4 hours.

2) Calculate the Total Electric Base Tank Power

Based on mechanical calculations on BaseTank the electrical specifications obtained with the formula (2.5)

1) ESC A (Electric Speed Control)

$$
\begin{aligned}
& P=V . I \\
& P=12 \text { V. } 0.2 A \\
& P=2.4 \mathrm{~W}
\end{aligned}
$$

2) ESC B (Electric Speed Control)

$$
\begin{aligned}
& P=V . I \\
& P=12 \text { V. } 0.2 A
\end{aligned}
$$




$$
\mathrm{P}=2.4 \mathrm{~W}
$$

3) Receiver

$$
\mathrm{P}=\mathrm{V} . \mathrm{I}
$$$$
P=6.5 \mathrm{~V} .0 .03 \mathrm{~A}
$$$$
\mathrm{P}=0.195 \mathrm{~W}
$$

4) DC Motor $\mathrm{A}$

$\mathrm{P}=\mathrm{V}$. I

$\mathrm{P}=12$ V. $8.5 \mathrm{~A}$

$\mathrm{P}=102 \mathrm{~W}$

5) DC Motor B

$$
\mathrm{P}=\mathrm{V} . \mathrm{I}
$$$$
\mathrm{P}=12 \mathrm{~V} .8 .5 \mathrm{~A}
$$$$
\mathrm{P}=102 \mathrm{~W}
$$

6) Servo motor

$$
\begin{aligned}
& P=V . I \\
& P=6.5 V .0 .01 A \\
& P=0.065 \mathrm{~W} \times(\text { Servo } 6) \\
& P=0.39 \mathrm{~W}
\end{aligned}
$$

From the specification data that has been obtained, the total electrical power needed:

$P_{\text {total }}=P_{1}+P_{2}+P_{3}+P_{4}+P_{5}+P_{6}$

$=2.4 \mathrm{~W}+2.4 \mathrm{~W}+0.195 \mathrm{~W}+102 \mathrm{~W}+102 \mathrm{~W}+0.39 \mathrm{~W}$ $=209,385 \mathrm{~W}$

So the total power of the Base Tank electrical specifications is $209,385 \mathrm{~W}$. Of the total power that has been calculated then to calculate the amperes using the formula (2.3) $\mathrm{I}=\frac{P}{V}$

$\mathrm{P}=$ Electric power using units of Watt $(\mathrm{W})$ $\mathrm{V}=$ Electric voltage using the unit of Volt $(\mathrm{V})$ $\mathrm{I}=$ Electric current uses units of Amphere (A) $I=\frac{209,385 w}{12 v}=17.45 \mathrm{~A}$

Assuming a minimum initial device can be operated for 1 hour during a grenade throwing exercise activity, then the minimum required battery capacity is $17.45 \mathrm{Ah}$.
Table 3. Battery Specifications / Manufacturers.

\begin{tabular}{|c|c|c|c|}
\hline Brand & Ah & volt & $\begin{array}{l}\text { Dimensi (P } \\
\mathbf{x} \text { L x T) cm }\end{array}$ \\
\hline Panasonic & 7,2 & 12 & $15 \times 6 \times 95$ \\
\hline Vabo & 18 & 12 & $18 \times 8 \times 17$ \\
\hline Yuasa & 20 & 12 & $20 \times 9 \times 19$ \\
\hline
\end{tabular}

Based on the above calculation, the authors determine the Vabo brand battery with a specification of $12 \mathrm{~V} 18$ Ah by adjusting the dimensions of the size of the electric space in the Base Tank. With a battery capacity of $18 \mathrm{Ah}$, the operating time of the Tool can be determined as follows,

Operating time $=\frac{18 \mathrm{Ah}}{17,45 \mathrm{~A}}=1.03$ hours

\subsection{Remote Control Testing}

This remote testing is needed to read the response of the ESC (Electric Speed Control) drive, DC motor and servo motor. By operating the buttons already on the remote, can be seen in Figure 4.

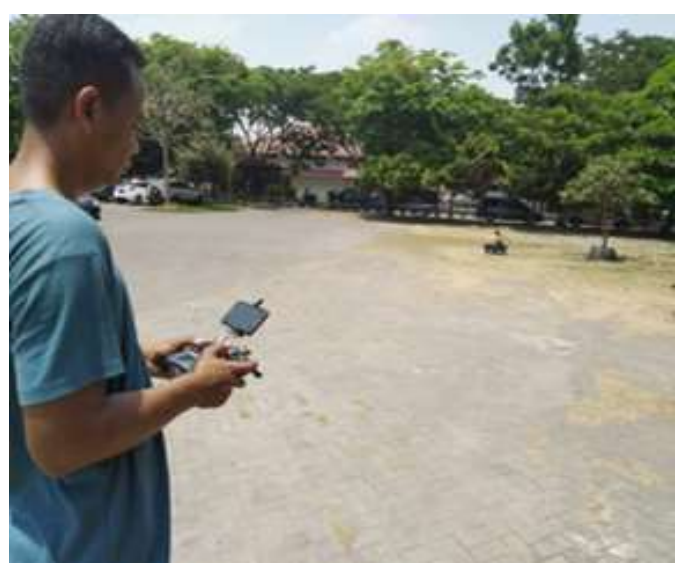

Fig.20 Remote control testing

Table 4. Remote Control Trial Distance

\begin{tabular}{|c|c|c|}
\hline NO & $\begin{array}{c}\text { DISTANCE } \\
\text { (METER) }\end{array}$ & RESULT \\
\hline 1 & 10 & current connection \\
\hline 2 & 20 & current connection \\
\hline 3 & 30 & current connection \\
\hline 4 & 40 & current connection \\
\hline 5 & 50 & current connection \\
\hline
\end{tabular}




\begin{tabular}{|c|c|c|}
\hline NO & $\begin{array}{c}\text { DISTANCE } \\
\text { (METER) }\end{array}$ & RESULT \\
\hline 6 & 60 & current connection \\
\hline 7 & 70 & current connection \\
\hline 8 & 80 & current connection \\
\hline 9 & 90 & current connection \\
\hline 10 & 100 & current connection \\
\hline 11 & 110 & current connection \\
\hline 12 & 120 & current connection \\
\hline 13 & 130 & current connection \\
\hline 14 & 140 & current connection \\
\hline 15 & 150 & current connection \\
\hline 16 & 160 & current connection \\
\hline 17 & 170 & constant connection \\
\hline 18 & 180 & connected connection \\
\hline
\end{tabular}

\subsection{Testing the Kogan HD 1080P Action} Camera

In testing the Action Camera that the author did was to test the distance of the wifi connection and do video streaming on the screen of an android mobile phone using the XDV application via play store. The next step is to provide a stimulus or treat it on the Action Camera ie treat it when the room is fully lighting (outdoor) and treat it when the room is under moderate lighting (indoors). The following screen shoots from the Action Camera test results with different stimuli. Looking at the results of Figure 21 and Figure 22 in both Action Camera testing in outdoor and indoor conditions, it can be concluded that the Action Camera can work well.

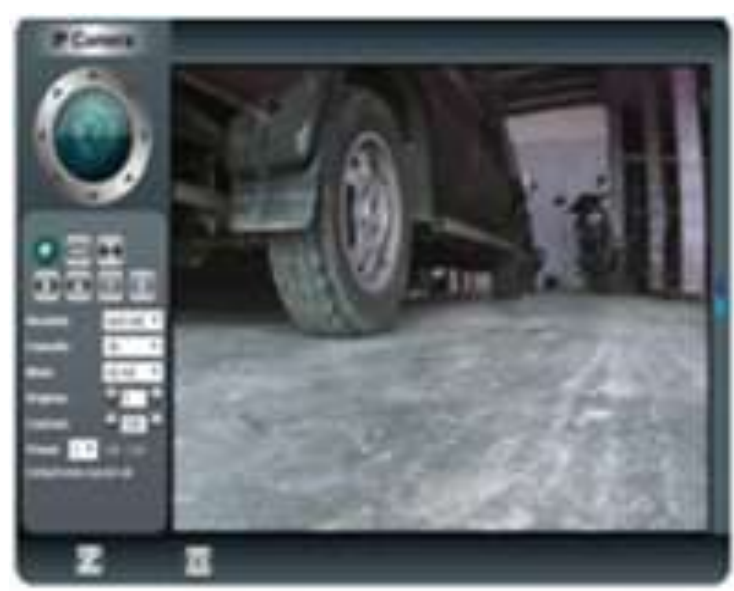

Fig.21 Outdoor Shooting (Source: Self-processed Results)

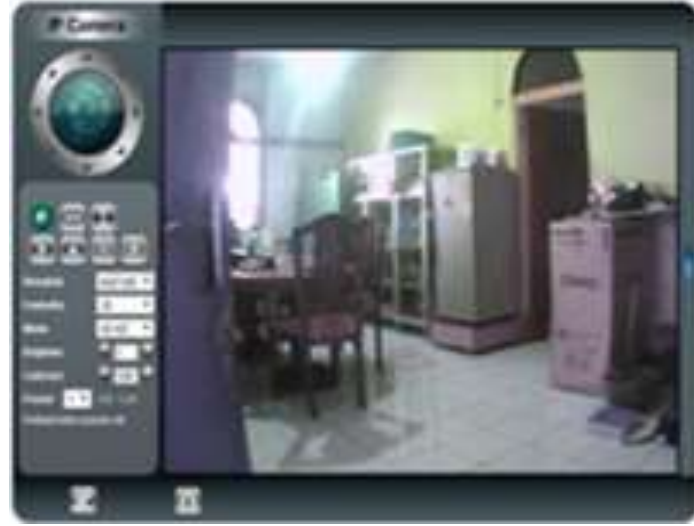

Fig.22 Shooting in the Room (Source: Self-processed Results)

Next is the testing distance of the wifi action camera mounted on the robot tank aims to find out how far the wifi camera's distance is with the control unit or controller, so that the test data is expected to be input for operators in controlling the robot tank. The testing process is not difficult, it just requires a large space, for that reason, in the process of testing the distance of the wifi transmission using outdoor or outdoor measurements, namely in the field. From the process of testing the wifi camera transmit distance on the robot tank, in an outdoor area, we get a table of test results as in Table 1 . From table 1 it can be said that the maximum distance between the operator and the robot is 20 meters maximum in the outdoor area.

Table 5. Results Data Distance Wifi Streaming

\begin{tabular}{|c|c|c|c|}
\hline NO & $\begin{array}{c}\text { Distance } \\
\text { (Meter) }\end{array}$ & $\begin{array}{c}\text { Video } \\
\text { Streaming }\end{array}$ & $\begin{array}{c}\text { Connection } \\
\text { Wifi }\end{array}$ \\
\hline 1 & 5 & success & Connected \\
\hline 2 & 10 & success & Connected \\
\hline 3 & 15 & success & Connected \\
\hline 4 & 20 & success & Connected \\
\hline 5 & 25 & Faltered & Faltered \\
\hline 6 & 30 & Disconnected & Disconnected \\
\hline
\end{tabular}

\subsection{Joystick Button Testing}

Next is testing the navigation buttons on the joystick, to give commands to move the robot arm prototype. The process is to move the Analog 
button and see how the robot arm moves, whether it responds or not. In table 6 testing the joystick button.

Table 6. Joystick Button Testing

\begin{tabular}{|l|l|l|l|c|}
\hline NO & CONTROL & FUNCTION & NFORMATION & RESULTS \\
\hline 1 & Analog E & Servo 2 & Arm Up & ok \\
\hline 2 & Analog F & Servo 2 & Arm Down & ok \\
\hline 3 & Analog G & Servo 1 & Arm Up & ok \\
\hline 4 & Switch H & Servo 4 & Gripper spinning 90' CW & ok \\
\hline 5 & Switch I & Servo 4 & Gripper spinning 90' CCW & ok \\
\hline 6 & Potensio L & Servo 3 & Arm Down & ok \\
\hline 7 & Potensio M & Servo 3 & Arm Up & ok \\
\hline 8 & Potensio O & Servo 6 & Foundation Arm Right & ok \\
\hline 9 & Potensio P & Servo 6 & Foundation Arm Left & ok \\
\hline 10 & Analog S & Servo 1 & Move Down & ok \\
\hline 11 & Analog Up A & Kontrol Motor DC & Wheel moves forward & ok \\
\hline 12 & Analog Down B & control Motor DC & wheel moves bachwards & ok \\
\hline 13 & Analog Left C & control Motor DC & wheel moves left & ok \\
\hline 14 & Analog Right D & control Motor DC & wheel moves right & ok \\
\hline 15 & Switch J Down & Servo 5 & Gripper opens & ok \\
\hline 16 & Switch KUp & Servo 5 & Gripper loses & ok \\
\hline
\end{tabular}

\subsection{Testing Time of Unmanned Grenade} Tamer.

In testing, the robot's mileage time is calculated. Starting from the initial position of the Start, move by carrying TNT towards the unexploded grenade, then placing TNT on the grenade to be detonated. After that the robot returns to the starting position Start. For the distance tested is 20 meters. Retrieval of robot travel time was carried out in 5 experiments.

Table 7. Travel Time of Robot Movement

\begin{tabular}{|c|c|c|c|}
\hline NO & $\begin{array}{c}\text { PERCO } \\
\text { BAAN }\end{array}$ & $\begin{array}{c}\text { WAKTU } \\
\text { TEMPUH }\end{array}$ & $\begin{array}{c}\text { KETERANG } \\
\text { AN }\end{array}$ \\
\hline 1 & 1 & 8,05 minute & success \\
\hline 2 & 2 & 8,55 minute & success \\
\hline 3 & 3 & 8,10 minute & success \\
\hline 4 & 4 & 8,07 minute & success \\
\hline 5 & 5 & 8,01 minute & success \\
\hline
\end{tabular}

The time difference that occurred in the above experiment was caused by several factors, namely, the laying and taking of grenades with different times as well as the difference in robot maneuvers when walking towards a safe place for blasting grenades. From 5 times the data collection, the average working time:

$$
\begin{aligned}
& \frac{8.05+8.02+8.10+8.07+8.01}{5} \\
& =\frac{40,25}{5}=8,05 \text { minutes }
\end{aligned}
$$

Rounded up to 8 minutes once the process of taking grenades from start to finish.

Next will be discussed about the results of tests that have been carried out, namely by calculating the power needed to run the controls on Unmanned Grenade Tamer. The results of tests that have been done get good results, so with this the author will calculate the power consumption required by the robot when it is operated from start to finish. From the test results obtained the average time needed for one operation is 8 minutes. Then the writer can calculate the power consumption of the Base Tank and control mechanism.

Based on the calculation that the author has discussed above, the writer can calculate the total duration of the operation of the Unmanned Grenade tamer robot. The duration is used to calculate the total power consumption used in a series of operations.

If the total electrical power specifications are $209.338 \mathrm{~W}$ and one operation takes 8 minutes then it can be calculated as follows.

The maximum time on a predetermined battery is 1.03 hours if converted to minutes is equivalent to 61.8 minutes, this tool can be operated as many as:

$\frac{61.8 \text { minutes }}{8 \text { minutes }}=7,725$ operations

\section{CONCLUSIONS}

\subsection{Conclusion}

After carrying out the Design Process and testing carried out on Unmanned Grenade Tamer, the following conclusions can be drawn: 
a. Design of this remote control writer Uses a circuit in the form of Flysky $10 \mathrm{CH}$ Transceiver, which uses a wireless network and uses air as a connecting channel using the $2.4 \mathrm{GHz}$ frequency band. Work orders are accepted and then modulated by the transceiver, after modulation the signal will be sent through an antenna in the form of a radio signal.

b. In this Unmanned Grenade Tamer robot uses an Accu Battery with a capacity of 12 VDC 18 Ah, for power consumption in one operation 209,385 W, if in one operation takes 8 minutes then this tool can be used as many as 7 times the operation.

\subsection{Suggestion}

The design of the Unmanned Grenade Tamer with wireless control still requires development suggestions based on the results of tests that have been carried out, as follows:

a. Please get an increase in the wifi signal by using a router on the camera so that the distance of the object detectors are further away.

b. Please obtain this final project to be further developed to support training activities in educational institutions and the assignment of the Navy in particular the TNI in general.

\section{REFERENCES}

Agung Gde Ekayana, G. N. 2017. Design a prototype control system for the robot arm using a $2.4 \mathrm{GHz}$ wirelles interface. science and technology, 2548-8570.
Atmoko, B. 2009, June 1. Bandung aeromodeling. Taken back from PT.Telenetina STU: https://www.oocities.org/tinbdg/About_Us.htm

Dermanto, T. 2014, March 19. Servo Motor. Retrieved from Control System Design: http://trikueni-desain-sistem.blogspot.com /p/blog-profil-my-name-is-trikuenidermanto.html

Ngabei, J. D. 2012, November 25. dc-chopper-typebuck-buck-converter.html.

Nur Shabrina, O. 2014. Receiver, Transmitter, timer. Electrical engineering. Electronics Nuclear engineering, 11-21.

Panjaitan, S. N. (2018). Learning basic physics and basic electronics (current, resistance and electrical voltage) using the matlab application simulink method. Physics Alumni Association of Medan State University, 24611247.

Prihatmoko, D. 2016. Design and implementation of room temperature controller based on Arduino Uno microcontroller. symmetrical, 2252-4983.

Rifai, E. Y. 2015, August 21. Action Camera. Retrieved from Jalan Tius: https://jalantikus.com/gadgets/tips-beliaction-camera-gopro/

Rudi Arfiansyah, Y. F. 2012. Android Application for Room Control and Monitoring Using IP Camera. Applied Computer Literacy, 1-2.

Siswandi Director. 2015, January 1. Serka TNI-AL Siswandi is the first bionic user in Indonesia [Motion Picture].

Suratno. (2016). Design and Build Stick Manipulators. Surabaya: Final Project. 